\title{
Stage I Superficial Spreading Melanoma AJCC v7
}

National Cancer Institute

\section{Source}

National Cancer Institute. Stage I Superficial Spreading Melanoma A/CC v7. NCI

Thesaurus. Code C8790.

Stage I includes: IA: (T 1a, N0, M0); IB: (T 1b, N0, M0); (T2a, N0, M0). T1a: Cutaneous melanoma with a tumor measuring $1.0 \mathrm{~mm}$ or less in thickness, without ulceration and mitosis less than $1 / \mathrm{mm} 2$. T1 b: Cutaneous melanoma with a tumor measuring $1.0 \mathrm{~mm}$ or less in thickness, with ulceration or mitoses equal to or more than 1/mm2. T2a: Cutaneous melanoma with a tumor measuring 1.01-2.0 mm in thickness, without ulceration. NO: No regional lymph node metastases. M0: No detectable evidence of distant metastases. (from AJCC 7th Ed.) 